\title{
Preparation, Characterization and Catalytic Activity of Alkyl Benzene Sulfonic Acid Carbon-Based Acid Catalyst
}

\author{
Huoxin Luan',2, Yunqiang $\mathrm{Wu}^{1}$, Wenxiang $\mathrm{Wu}^{2}$, Quansheng Chen1, Hailing Zhang1, \\ Kang Liu', Guangmiao Qu' ${ }^{2}$, Wei Ding ${ }^{2}$ \\ ${ }^{1}$ Xinjiang Oilfield Company, Xinjiang, China \\ ${ }^{2}$ Northeast Petroleum University, Daqing, China \\ Email: luanhuoxin1982@163.com
}

Received 3 March 2015; accepted 26 March 2015; published 31 March 2015

Copyright @ 2015 by authors and Scientific Research Publishing Inc.

This work is licensed under the Creative Commons Attribution International License (CC BY). http://creativecommons.org/licenses/by/4.0/

(c) (1) Open Access

\begin{abstract}
Based on starch and series of alkyl benzene sulfonic acid as the materials, a novel carbon-based solid acid catalyst is synthesized using hydrothermal method. This catalyst exhibits much higher catalytic activity in the reaction of esterification of Mono-fatty alcohol polyoxyethylene maleate esters with 1,4-butanediol. The structure of carbon-based solid acid catalyst was charactered by IR and XRD, characterizations showed that this catalyst exhibited high $-\mathrm{SO}_{3} \mathrm{H}$ loading. Reusability of the carbon-based solid acid catalyst for esterification showed that after recycling five times the activity remained unchanged.
\end{abstract}

\section{Keywords}

Alkyl Benzene Sulfonic Acid, Carbon-Based Solid Acid Catalyst, Esterification

\section{Introduction}

The principles of green chemistry and increasing concerns about environmental issues have stimulated the research for recyclable strong solid acids to replace of conventional toxic and corrosive acid catalysts, such as sulfuric acid [1]. Integration of acidic functional groups (e.g., $-\mathrm{SO}_{3} \mathrm{H}$ ) into solid surface, e.g. carbonaceous [2]-[5] or silica-based materials [6]-[9], has been explored to produce promising solid acids. Among them, the sulfonated carbon materials have received much attention due to their low costs, high stability, and high activities. Sulfonated carbonaceous materials were usually synthesized through the oxidation of carbon materials by sulfur acid [10] [12] or oleum [13] [14] to generate sulfonic acid groups on the surface. For example, Hara et al. 
[10] [11] obtained a series of carbon-based catalysts with acid densities ranging from 0.37 to $1.34 \mathrm{mmol} \mathrm{H}^{+} / \mathrm{g}$ by the sulfonation of incompletely carbonized sugars. Similarly, Budarin et al. [12] synthesized a mesoporous sulfonated Starbon- 400 with $0.5 \mathrm{mmol} / \mathrm{g} \mathrm{SO}_{3} \mathrm{H}$ loading. An ordered mesoporous phenol-formaldehyde resin [14] was also functionalized with sulfonate groups by putting the material in the vapor of fuming sulfuric acid inside an autoclave. Ryoo et al. [15] synthesized an ordered mesoporous carbons (OMCs) through the nanocasting technique using OMCS as templatesor via self-assembly of phenolic resins and block copolymers [16] [17]. These materials exhibit high surface area, narrow pore size distribution, and large pore volume. Recently, a new class of sulfonated carbons $\left(\mathrm{C}-\mathrm{SO}_{3} \mathrm{H}\right)$ derived from the incomplete carbonization of simple sugars and starch were reported to show excellent catalytic performance for the synthesis of biodiesel [18]-[20].

\section{Experiment Procedures}

Alkyl benzene sulfonic acid was synthesized according to the literature; fatty alcohol polyoxyethylene ether (AEO-3) was from Liao Yang Oak polyether Co., Ltd. (Liaoyang, Liaoning Province, China). The catalyst was synthesized according to the literature. Maleic anhydride (MAH) was obtained from Kemiou (Tianjin, China). Nitrogen was of high grade purity from Xue Long (99.99\% purity, Daqing, China). The IR spectra was obtained on a 4300 Shimadzu spectrophotometer as KBr disks. XRD (Rigaku, Tokyo, Japan).

\subsection{Synthesis of Alkyl Benzene Sulfonic Acid}

The synthesis procedure of alkyl benzene sulfonic acid is as shown in the References [21]-[24], and the molecular structure of alkyl aryl benzene sulfonic acid as following in Scheme 1.

\subsection{Synthesis of the Carbon-Based Solid Acid Catalyst}

In typical procedure: $15 \mathrm{~g}$ starch and $15 \mathrm{~g}$ sulfonic acid were mixed together and transferred to the quartz furnace. The mixture was heated to $200^{\circ} \mathrm{C}$ from room temperature with the heating rate of $1^{\circ} \mathrm{C} / \mathrm{min}$ and remained at $200^{\circ} \mathrm{C}$ for $12 \mathrm{~h}$ under nitrogen atmosphere. After cooling to room temperature, obtained black solid was washed with deionized water until no acidity detected in the filtrate. The novel solid acid was obtained after drying at $120^{\circ} \mathrm{C}$ overnight in an oven and grinding it into fine flour. P-toluene sulphonic acid carbon-based solid acid catalyst, tetradecyl benzene sulphonic acid carbon-based solid acid catalyst, hexadecyl benzene sulphonic acid carbon-based solid acid catalyst and octadecyle benzene sulphonic acid carbon-based solid acid catalyst are abbreviated in what follows as cat 1 , cat 2 , cat 3 , cat 4 respectively.

\subsection{Synthesis of Mono-Fatty Alcohol Polyoxyethylene Maleate Esters}

Mono-fatty alcohol polyoxyethylene maleate esters were synthesized by $0.1 \mathrm{~mol}(9.806 \mathrm{~g})$ of maleic anhydride (MAH) reacted to $0.1 \mathrm{~mol}(31.695 \mathrm{~g}, \mathrm{M}=317.695 \mathrm{~g} / \mathrm{mol}$ ) of fatty alcohol polyoxyethylene (AEO-3) and $0.1 \%$ (wt) p-toluene sulphonic acid served as a catalyst for $8 \mathrm{~h}$ with heating at $80^{\circ} \mathrm{C}$. Standard titration solution of $\mathrm{NaOH}$ was used to determine the system acid value, and when the variation of acid value was less than $1 \mathrm{mg} / \mathrm{h}$, it was regarded as near the end point of esterification. The crude product was recrystallized from ethanol and water $(\mathrm{V} / \mathrm{V}=1: 1)$ to three times. Compound 1a was obtained in $95.66 \%$.

\subsection{Synthesis of Bis(Mono-Fatty Alcohol Polyoxyethylene Maleate)1,4-Butanediol Ester}

$0.05 \mathrm{~mol}$ (20.515 g) of compound 1 reacted with $0.025 \mathrm{~mol}$ (2.253 g) of 1,4-butanediol and 1\% (wt) of carbonbased solid acid served as catalyst under vacuum degree of $-0.09 \mathrm{mpa}$ at $150^{\circ} \mathrm{C}$ reacting $10 \mathrm{~h}$. and real-time detection of acid value. The esterification rate was calculated using the following formula [25]-[27]: $(\mathrm{Er})=(1-$

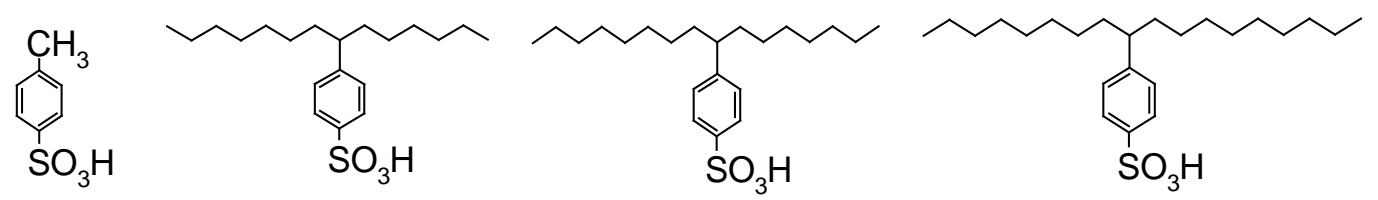

Scheme 1. The molecular structure of alkyl aryl benzene sulfonic acid. 
$\left.\mathrm{AV}_{\mathrm{a}} / \mathrm{AV}_{\mathrm{b}}\right) \times 100 \%$, where $\mathrm{Er}$ is esterification rate, $\mathrm{AV}_{\mathrm{a}}$ is Final acid value, $\mathrm{AV}_{\mathrm{b}}$ is Initial acid value. The typical procedure (Scheme 2).

\section{Results and Discussion}

The reaction mechanism is most probably like this: Firstly, the starch was dehydrated into small organic molecules, mainly 5-(hydroxymethyl)-2-furaldehyde (HMF) [28]-[30], and the generated HMF could be hydrothermally carbonized into a carbon-rich resin as well as react with alkyl benzene sulfonic acid to "embed" sulfonic acid groups as is shown in Scheme 3.

\subsection{Characterization of Carbon-Based Solid Acid Catalyst}

The FT-IR spectrum Figure 1 showed that the carbon-based solid acid contain resident functionalities including,

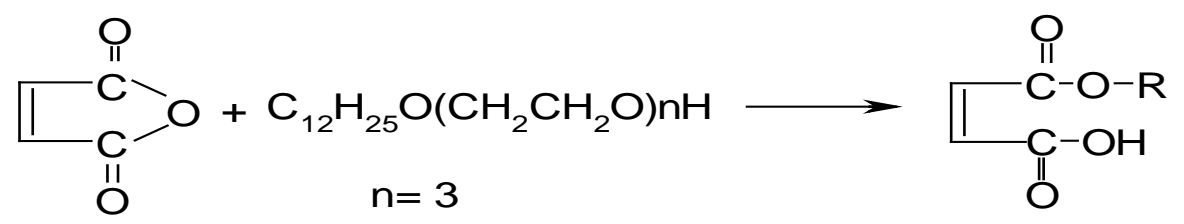<smiles>[R]OC(=O)CCCC(=O)OCCCOC(=O)CCCCCCOC(=O)O[R]</smiles>

Cat 1: p-toluene sulphonic acid catalyst, Cat 2: tetradecyl benzene sulphonic acid catalyst Cat 3: hexadecyl benzene sulphonic acid catalyst, Cat 4: octadecyle benzene sulphonic acid catalyst Scheme 2. Synthesis route of the reaction.

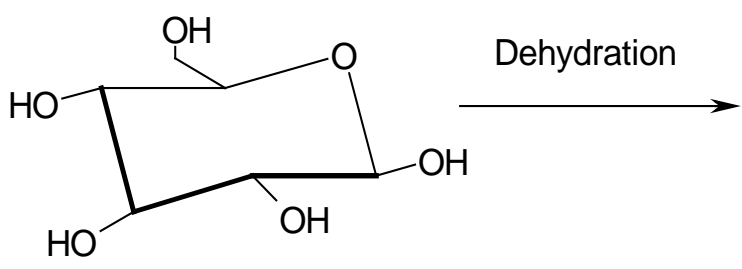<smiles>O=Cc1ccc(CO)o1</smiles>

Alkyl benzene sulphonic acid<smiles>[Y]C(C)(C)CC</smiles>

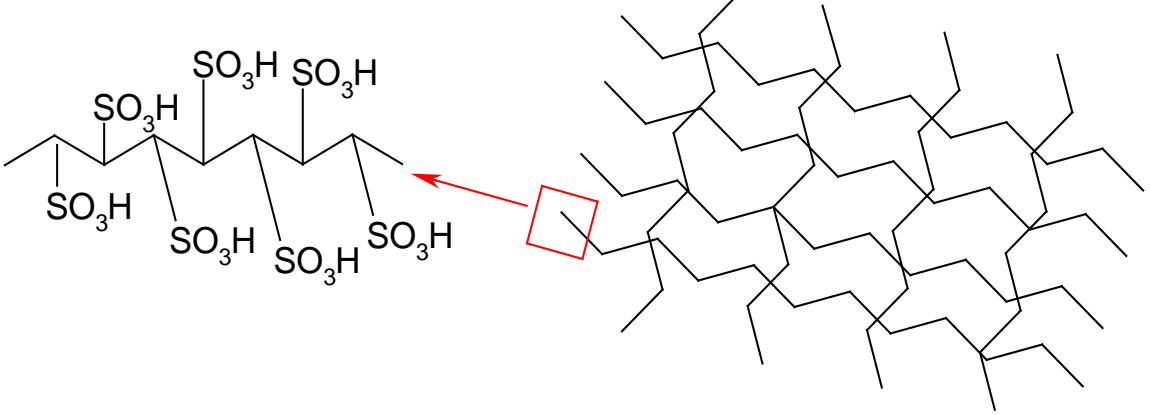

Scheme 3. Hydrothermal method to synthesis of carbon-based solid acid. 
$1007 \mathrm{~cm}^{-1}, 1032 \mathrm{~cm}^{-1}$ ( $\mathrm{S}=\mathrm{O} \mathrm{str}$ ). $1118 \mathrm{~cm}^{-1}$ ( $\mathrm{SO}_{3} \mathrm{H} \mathrm{str}$ ), $1710 \mathrm{~cm}^{-1}$ (C=O bend), $3450 \mathrm{~cm}^{-1}$ (OH str) On the other hand, the bands due to $-\mathrm{OH}$ stretching at $3420 \mathrm{~cm}^{-1}$, and $\mathrm{C}=\mathrm{C}$ bonds stretching at $1620 \mathrm{~cm}^{-1}$ were observed for both samples independent of the sulfonation. It is shown that the carbon-based solid acid have the group of $-\mathrm{SO}_{3} \mathrm{H}$.

The XRD pattern (Figure 2) contains two broad and weak diffraction peaks C (002) diffraction peak ( $2 \theta=$ $10^{\circ}-35^{\circ}$ ) attributable to amorphous carbon composed of aromatic carbon sheets oriented in a considerably ran

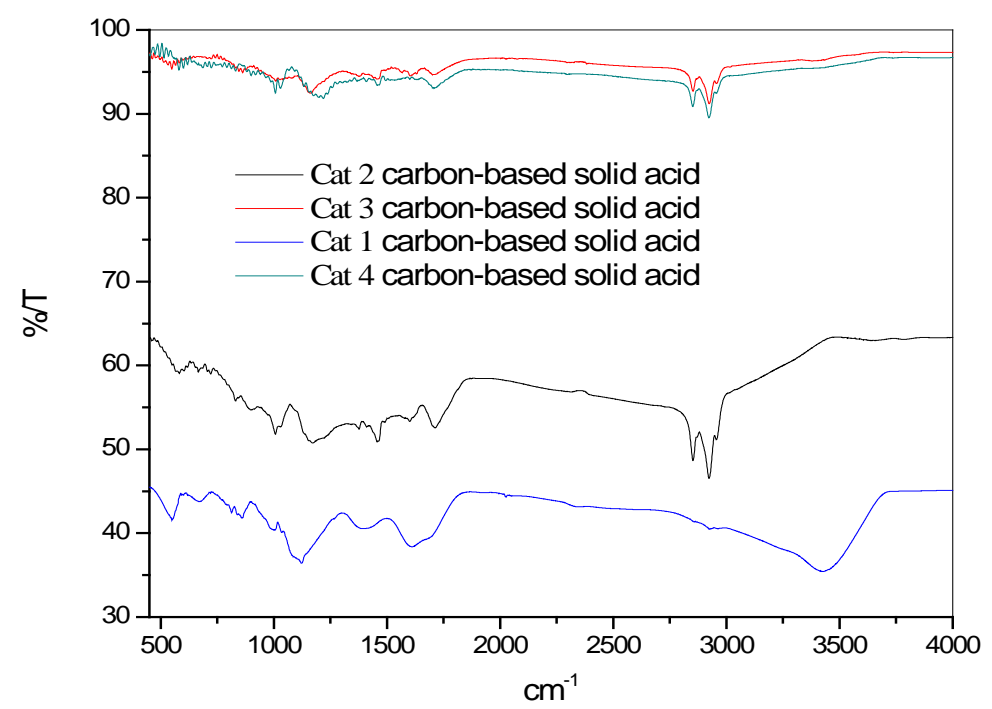

Cat 1: p-toluene sulphonic acid catalyst, Cat 2: tetradecyl benzene sulphonic acid catalyst

Cat 3: hexadecyl benzene sulphonic acid catalyst, Cat 4: octadecyle benzene sulphonic acid catalyst

The IR spectra was obtained on a 4300 Shimadzu spectrophotometer as $\mathrm{KBr}$ disks.

Figure 1. FT-IR spectrum of carbon-based solid acid.

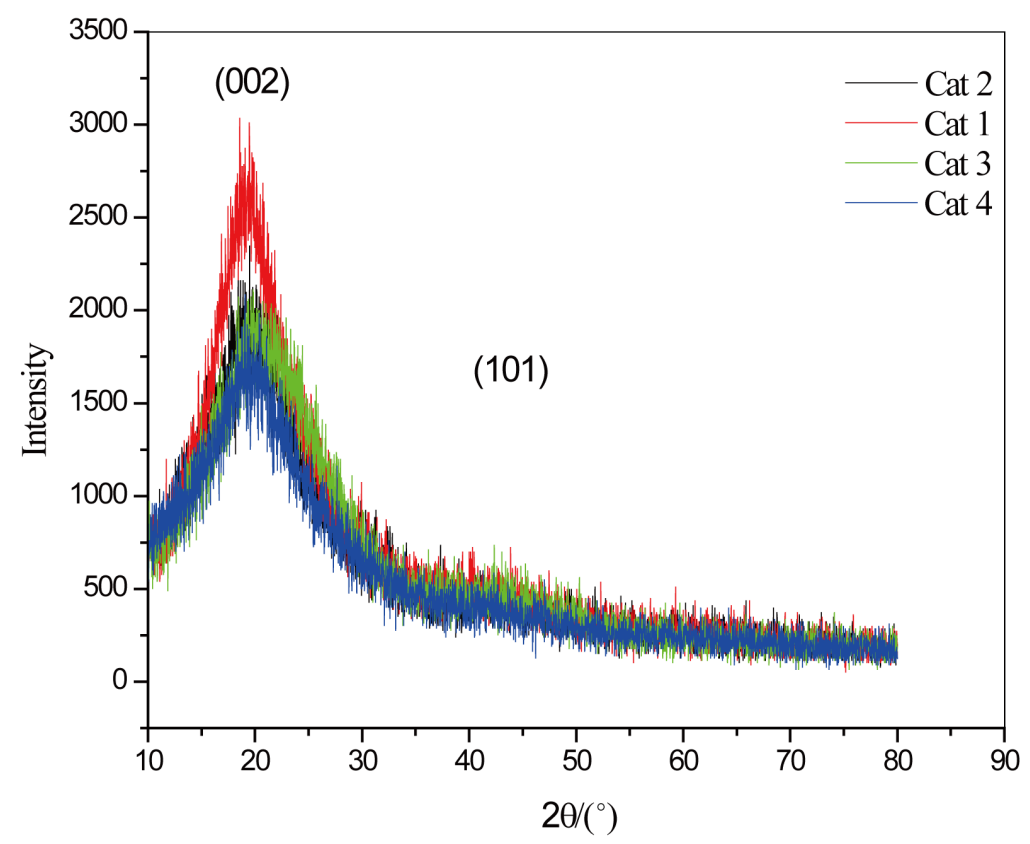

Cat 1: p-toluene sulphonic acid catalyst, Cat 2: tetradecyl benzene sulphonic acid catalyst

Cat 3: hexadecyl benzene sulphonic acid catalyst, Cat 4: octadecyle benzene sulphonic acid catalyst

Figure 2. XRD of carbon-based solid acid XRD (Rigaku, Tokyo, Japan). 
dom fashion. A definitive C (101) diffraction peak $\left(2 \theta=35^{\circ}-45^{\circ}\right)$ due to the a axis of the graphite structure can be seen. The X-ray diffractogram is similar to that of char because the sulfonic acid groups were attached to edges of isotropic carbon sheets and the solid acid exhibits broad diffraction peaks of amorphous carbon [31]-[33].

\subsection{Qrthogonal Experiment of Cat 1 Carbon-Based Solid Acid}

The optimum reaction conditions from Table 1 was obtained as follows: $\mathrm{m}_{\text {starch }}: \mathrm{m}_{\text {cat } 1}=1: 1$, reaction temperature: $220^{\circ} \mathrm{C}$, reaction time: $10 \mathrm{~h}$, All results were repeated for three times: Esterification rate were $91.85 \%$, 90.63\% and $90.71 \%$ respectively, average value was $91.06 \%$.

\subsection{Qrthogonal Experiment of Cat 2 Carbon-Based Solid Acid}

The optimum reaction conditions from Table 2 was obtained as follows: reaction temperature: $180^{\circ} \mathrm{C}$; reaction Table 1. Qrthogonal experiment of Cat 1 carbon-based solid acid.

\begin{tabular}{ccccc}
\hline Factor & Temperature $/{ }^{\circ} \mathrm{C}$ & Hour $/ \mathrm{h}$ & $\mathrm{m}_{\text {starc }}: \mathrm{m}_{\text {cat }}{ }^{*}$ & Esterification rate $/ \%$ \\
\hline Experiment 1 & 180 & 8 & $1: 1$ & 91.57 \\
Experiment 2 & 200 & 10 & $1: 1$ & 90.49 \\
Experiment 3 & 220 & 12 & $1:$ & 85.88 \\
Experiment 4 & 180 & 10 & $2: 1$ & 87.13 \\
Experiment 5 & 200 & 12 & $2: 1$ & 88.65 \\
Experiment 6 & 220 & 8 & $2: 1$ & 90.12 \\
Experiment 7 & 180 & 12 & $3: 1$ & 87.12 \\
Experiment 8 & 200 & 8 & $3: 1$ & 85.89 \\
Experiment 9 & 220 & 10 & $3: 1$ & 91.72 \\
Average 1 & 88.607 & 89.193 & 89.313 & 88.633 \\
Average 2 & 88.343 & 89.780 & 88.243 & \\
Average 3 & 89.240 & 87.217 & 1.070 & \\
Standard deviation & 0.897 & 2.563 & 8.12 & \\
\hline
\end{tabular}

*Average 1 is experiments 1, 4, 7; Average 2 is 2, 5, 8; Average 3 is 3, 6, 9.

Table 2. Qrthogonal experiment of Cat 2 carbon-based solid acid.

\begin{tabular}{|c|c|c|c|c|}
\hline Factor & Temperature $/{ }^{\circ} \mathrm{C}$ & Hour/h & $\mathrm{m}_{\text {starch }}: \mathrm{m}_{\mathrm{cat} 2}$ & Esterification rate/\% \\
\hline Experiment 1 & 180 & 8 & $1: 1$ & 93.92 \\
\hline Experiment 2 & 180 & 10 & $2: 1$ & 90.82 \\
\hline Experiment 3 & 180 & 12 & $3: 1$ & 88.52 \\
\hline Experiment 4 & 200 & 8 & $2: 1$ & 90.27 \\
\hline Experiment 5 & 200 & 10 & $3: 1$ & 89.99 \\
\hline Experiment 6 & 200 & 12 & $1: 1$ & 89.35 \\
\hline Experiment 7 & 220 & 8 & $3: 1$ & 71.17 \\
\hline Experiment 8 & 220 & 10 & $1: 1$ & 88.15 \\
\hline Experiment 9 & 220 & 12 & $2: 1$ & 85.98 \\
\hline Average 1 & 91.087 & 85.120 & 90.473 & \\
\hline Average 2 & 89.870 & 89.653 & 89.023 & \\
\hline Average 3 & 81.767 & 87.950 & 83.227 & \\
\hline Standard deviation & 9.320 & 4.533 & 7.246 & \\
\hline
\end{tabular}

*Average 1 is experiments 1, 4, 7; Average 2 is 2, 5, 8; Average 3 is 3, 6, 9. 
time: $10 \mathrm{~h} ; \mathrm{m}_{\mathrm{starch}}: \mathrm{m}_{\text {cat2 }}=1: 1$, All results were repeated for three times: Esterification rate were $88.04 \%, 86.98 \%$ and $90.82 \%$, average value was $88.61 \%$.

\subsection{Qrthogonal Experiment of Cat 3 Carbon-Based Solid Acid}

The optimum reaction conditions from Table 3 was obtained as follows: reaction temperature: $220^{\circ} \mathrm{C}$, reaction time: $10 \mathrm{~h}, \mathrm{~m}_{\text {starch }}: \mathrm{m}_{\text {cat3 }}=1: 3$, All results were repeated for three times: Esterification rate were $91.08 \%, 89.42 \%$ and $89.92 \%$, average value was $90.14 \%$.

\subsection{Qrthogonal Experiment of Cat 4 Carbon-Based Solid Acid}

The optimum reaction conditions from Table 4 was obtained as follows: reaction temperature: $180^{\circ} \mathrm{C}$; reaction time: $12 \mathrm{~h} ; \mathrm{m}_{\text {starch}}: \mathrm{m}_{\text {cat } 4}=1: 1$, All results were repeated for three times: Esterification rate were $90.07 \%$, 91.98\% and $93.06 \%$, average value was $91.70 \%$.

Table 3. Qrthogonal experiment of Cat 3 carbon-based solid acid.

\begin{tabular}{ccccc}
\hline Factor & Temperature $/{ }^{\circ} \mathrm{C}$ & Hour $/ \mathrm{h}$ & $\mathrm{m}_{\text {starch }}: \mathrm{m}_{\text {cat3 }}$ & Esterification rate $/ \%$ \\
\hline Experiment 1 & 180 & 8 & $1: 1$ & 80.02 \\
Experiment 2 & 180 & 10 & $2: 1$ & 81.18 \\
Experiment 3 & 180 & 12 & $3: 1$ & 84.11 \\
Experiment 4 & 200 & 8 & $2: 1$ & 80.38 \\
Experiment 5 & 200 & 10 & $3: 1$ & 80.94 \\
Experiment 6 & 200 & 12 & $1: 1$ & 77.39 \\
Experiment 7 & 220 & 8 & $3: 1$ & 90.23 \\
Experiment 8 & 220 & 10 & $1: 1$ & 90.67 \\
Experiment 9 & 220 & 12 & $2: 1$ & 91.29 \\
Average 1 & 81.770 & 83.543 & 82.693 & \\
Average 2 & 79.570 & 84.263 & 84.283 & \\
Average 3 & 90.730 & 84.263 & 85.093 & \\
Standard deviation & 11.160 & 0.720 & 2.400 & \\
\hline
\end{tabular}

*Average 1 is experiments 1, 4, 7; Average 2 is 2, 5, 8; Average 3 is 3, 6, 9.

Table 4. Qrthogonal experiment of Cat 4 carbon-based solid acid.

\begin{tabular}{|c|c|c|c|c|}
\hline Factor & Temperature $/{ }^{\circ} \mathrm{C}$ & Hour/h & $\mathrm{m}_{\text {starch }}: \mathrm{m}_{\mathrm{cat} 4}$ & Esterification rate/\% \\
\hline Experiment 1 & 180 & 8 & $1: 1$ & 89.11 \\
\hline Experiment 2 & 180 & 10 & $2: 1$ & 89.68 \\
\hline Experiment 3 & 180 & 12 & $3: 1$ & 91.26 \\
\hline Experiment 4 & 200 & 8 & $2: 1$ & 90.1 \\
\hline Experiment 5 & 200 & 10 & $3: 1$ & 83.84 \\
\hline Experiment 6 & 200 & 12 & $1: 1$ & 90.53 \\
\hline Experiment 7 & 220 & 8 & $3: 1$ & 86.9 \\
\hline Experiment 8 & 220 & 10 & $1: 1$ & 91.93 \\
\hline Experiment 9 & 220 & 12 & $2: 1$ & 87.81 \\
\hline Average 1 & 90.017 & 88.703 & 90.523 & \\
\hline Average 2 & 88.157 & 88.483 & 89.197 & \\
\hline Average 3 & 88.880 & 89.867 & 87.333 & \\
\hline Standard deviation & 1.860 & 1.384 & 3.190 & \\
\hline
\end{tabular}

*Average 1 is experiments 1, 4, 7; Average 2 is 2, 5, 8; Average 3 is 3, 6, 9. 


\subsection{Comparison of Catalytic Activities}

The esterification at $0.05 \mathrm{~mol}$ (20.515 g) of compound 1a reacted to $0.025 \mathrm{~mol}$ (2.253g) of 1,4-butanediol and $1 \%$ (wt) of carbon-based solid acid was used as catalyst under vacuum degree of $-0.09 \mathrm{mpa}$ at $150^{\circ} \mathrm{C}$ reacting $10 \mathrm{~h}$. From Figure 3 we can see that alkyl benzene sulfonic acid carbon-based solid acid catalyst (cat2, cat3, cat4) has the same catalytic activity with p-toluene sulphonic acid carbon-based solid acid catalyst (cat1) in the reaction of esterification of Mono-fatty alcohol polyoxyethylene maleate esters with 1,4-butanediol.

The reusability of the alkyl benzene sulfonic acid carbon-based solid acid catalyst was investigated for the reaction of esterification. After the reaction had reached equilibrium, the novel carbon-based acid was simply recovered by filtration and recycled for further reaction. It was confirmed that the activity remained unchanged, even after the catalyst had been recycled five times (Figure 4).

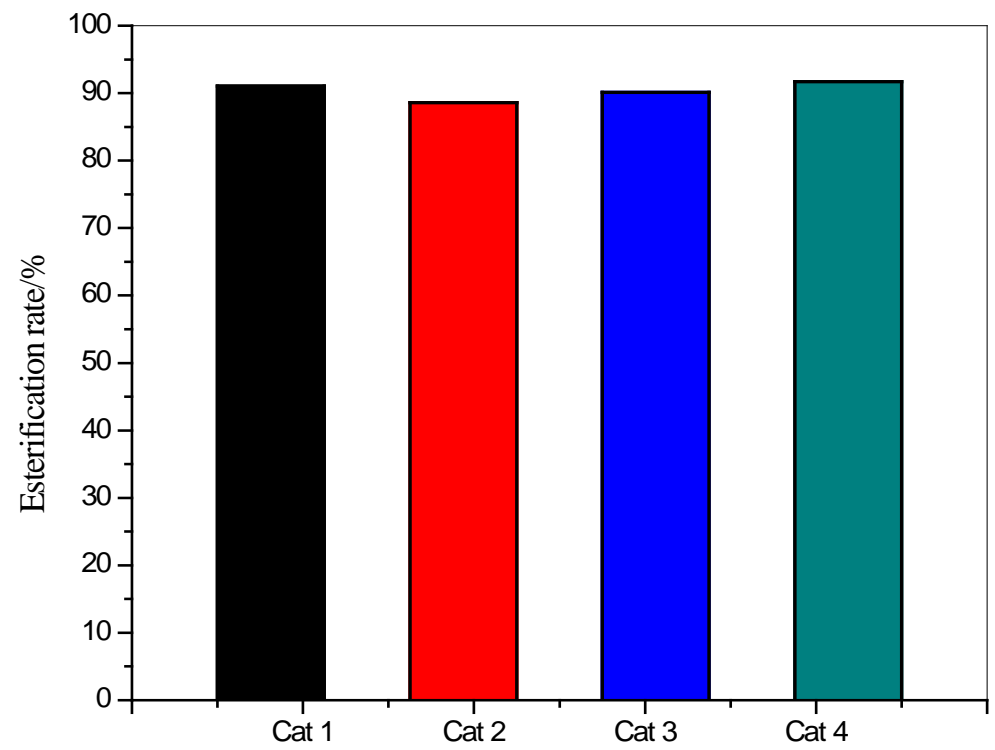

Figure 3. Catalytic activity.

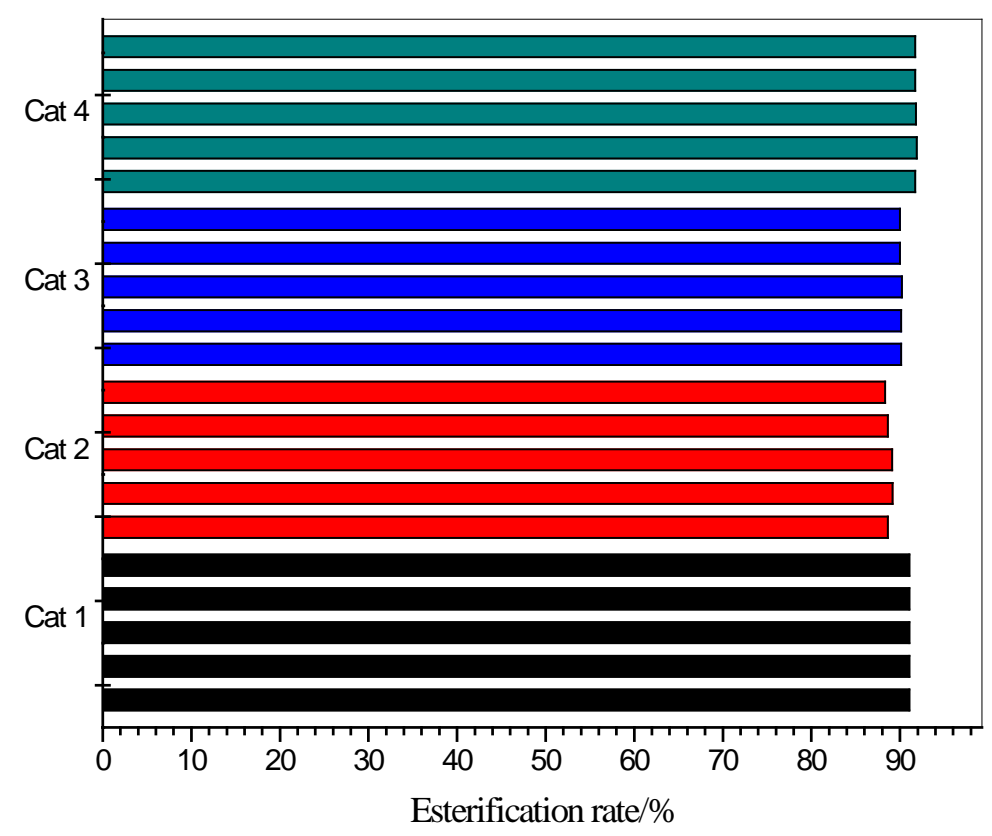

Figure 4. Reusability of carbon-based solid acid catalyst for esterification. 


\section{Conclusion}

A novel and facile method for preparing highly active carbon-based solid-acid catalyst functionalized with sulfonic acid groups was reported. In this method, alkyl benzene sulfonic acid was used in the synthesis instead of concentrated/fuming sulfur acid and the preparation was made safer by avoiding usage of dangerous chemicals. The so-prepared catalyst exhibits much higher catalytic activity in the reaction of esterification of Mono-fatty alcohol polyoxyethylene maleate esters with 1,4-butanediol. The cycle usage test indicated that the catalyst prepared by this method was relative stable.

\section{Acknowledgements}

This research was financially supported by the National Key Basic Research Development Program (2005CB221305), the National Natural Science Foundation of China (No. 50174033).

\section{References}

[1] Clark, J.H. (2002) Solid Acids for Green Chemistry. Accounts of Chemical Research, 35, 791-797. http://dx.doi.org/10.1021/ar010072a

[2] Budarin, V., Clark, J.H., Hardy, J.J., Luque, R., Milkowski, K., Tavener, S.J. and Wilson, A.J. (2006) Starbons: New StarchDerived Mesoporous Carbonaceous Materials with Tunable Properties. Angewandte Chemie International Edition, 45, 3782-3786. http://dx.doi.org/10.1002/anie.200600460

[3] Hara, M., Yoshida, T., Takagaki, A., Takata, T., Kondo, J.N. and Hayashi, S. (2004) A Carbon Material as a Strong Protonic Acid. Angewandte Chemie International Edition, 43, 2955-2958. http://dx.doi.org/10.1002/anie.200453947

[4] Nakajima, K. and Hara, M. (2009) Amorphous Carbon Bearing Sulfonic Acid Groups in Mesoporous Silica as a Selective Catalyst. Chemistry of Materials, 21, 186-193. http://dx.doi.org/10.1021/cm801441c

[5] Wang, X., Liu, R., Waje, M.M., Chen, Z., Yan, Y., Bozhilov, K.N. and Feng, P. (2007) Sulfonated Ordered Mesoporous Carbon as a Stable and Highly Active Protonic Acid Catalyst. Chemistry of Materials, 19, 2395-2397. http://dx.doi.org/10.1021/cm070278r

[6] (a) Margolese, D., Melero, J.A., Christiansen, S.C., Chmelka, B.F. and Stucky, G.D. (2000) Direct Syntheses of Ordered SBA-15 Mesoporous Silica Containing Sulfonic Acid Groups. Chemistry of Materials, 12, 2448-2459.

(b) Melero, J.A., Stucky, G.D., van Grieken, R. and Morales, G. (2002) Direct Syntheses of Ordered SBA-15 Mesoporous Materials Containing Arenesulfonic Acid Groups. Journal of Materials Chemistry, 12, 1664-1670. http://dx.doi.org/10.1039/b110598c

[7] Dufaud, V., Davis, M.E. (2003) Design of Heterogeneous Catalysts via Multiple Active Site Positioning in OrganicInorganic Hybrid Materials. Journal of the American Chemical Society, 125, 9403-9413. http://dx.doi.org/10.1021/ja034594s

[8] (a) Das, D., Lee, J.F. and Cheng, S. (2001) Sulfonic Acid Functionalized Mesoporous MCM-41 Silica as a Convenient Catalyst for Bisphenol-A Synthesis. Chemical Communications, 2178-2179.

(b) Das, D. and Cheng, S. (2004) Selective Synthesis of Bisphenol-A over Mesoporous MCM Silica Catalysts Functionalized with Sulfonic Acid Groups. Journal of Catalysis, 223, 152-160. http://dx.doi.org/10.1016/j.jcat.2004.01.025

[9] Macquarrie, D.J., Tavener, S.J. and Harmer, M.A. (2005) Novel Mesoporous Silica-Perfluorosulfonic Acid Hybrids as Strong Heterogeneous Brønsted Catalysts. Chemical Communications, 2363-2365. http://dx.doi.org/10.1039/b501431j

[10] Toda, M., Takagaki, A., Okamura, M., Kondo, J.N., Hayashi, S., Domen, K. and Hara, M. (2005) Green Chemistry: Biodiesel Made with Sugar Catalyst. Nature, 438, 178. http://dx.doi.org/10.1038/438178a

[11] Okamura, M., Takagaki, A., Toda, M., Kondo, J.N., Domen, K., Tatsumi, T., Hara, M. and Hayashi, S. (2006) AcidCatalyzed Reactions on Flexible Polycyclic Aromatic Carbon in Amorphous Carbon. Chemistry of Materials, 18, 3039-3045. http://dx.doi.org/10.1021/cm0605623

[12] Budarin, V.L., Clark, J.H., Luque, R. and Macquarrie, D.J. (2007) Versatile Mesoporous Carbonaceous Materials for Acid Catalysis. Chemical Communications, 2007, 634-636. http://dx.doi.org/10.1039/B614537J

[13] Xing, R., Liu, Y., Wang, Y., Chen, L., Wu, H., Jiang, Y., He, M. and Wu, P. (2007) Active Solid Acid Catalysts Prepared by Sulfonation of Carbonization-Controlled Mesoporous Carbon Materials. Microporous and Mesoporous Materials, 105, 41-48. http://dx.doi.org/10.1016/j.micromeso.2007.06.043

[14] Xing, R., Liu, N., Liu, Y., Wu, H., Jiang, Y., Chen, L., He, M. and Wu, P. (2007) Novel Solid Acid Catalysts: Sulfonic Acid Group-Functionalized Mesostructured Polymers. Advanced Functional Materials, 17, 2455-2461. http://dx.doi.org/10.1002/adfm.200600784

[15] (a) Ryoo, R., Joo, S.H. and Jun, S. (1999) Synthesis of Highly Ordered Carbon Molecular Sieves via Template-Mediat- 
ed Structural Transformation. The Journal of Physical Chemistry B, 103, 7743-7746.

http://dx.doi.org/10.1021/jp991673a

(a) Ryoo, R., Joo, S.H. and Jun, S. (1999) Synthesis of Highly Ordered Carbon Molecular Sieves via Template-Mediated Structural Transformation. The Journal of Physical Chemistry B, 103, 7743-7746.

http://dx.doi.org/10.1021/jp991673a

(c) Joo, S.H., Choi, S.J., Oh, I., et al. (2001) Ordered Nanoporous Arrays of Carbon Supporting High Dispersions of Platinum Nanoparticles. Nature, 412, 169-172. http://dx.doi.org/10.1038/35084046

[16] (a) Zhang, F.Q., Meng, Y., Gu, D., Yan, Y., Yu, C.Z., Tu, B. and Zhao, D.Y. (2005) Facile Aqueous Route to Synthesize Highly Ordered Mesoporous Polymers and Carbon Frameworks with Ia3d Bicontinuous Cubic Structure. Journal of the American Chemical Society, 127, 13508-13509. http://dx.doi.org/10.1021/ja0545721

(b) Meng, Y., Gu, D., Zhang, F., Shi, Y., Yang, H., Li, Z., Yu, C., Tu, B. and Zhao, D. (2005) Ordered Mesoporous Polymers and Homologous Carbon Frameworks: Amphiphilic Surfactant Templating and Direct Transformation. Angewandte Chemie International Edition, 44, 7053-7059. http://dx.doi.org/10.1002/anie.200501561

(c) Liang, C.D. and Dai, S.J. (2006) Synthesis of Mesoporous Carbon Materials via Enhanced Hydrogen-Bonding Interaction. Journal of the American Chemical Society, 128, 5316-5317. http://dx.doi.org/10.1021/ja060242k

[17] Wang, X.-Q., Liu, R., Waje, M.M., Chen, Z.W., Yan, Y.S., Bozhilov, K.N. and Feng, P.Y. (2007) Sulfonated Ordered Mesoporous Carbon as a Stable and Highly Active Protonic Acid Catalyst. Chemistry of Materials, 19, $2395-2397$.

[18] Takagakia, A., Todaa, M., Okamuraa, M., Kondoa, J.N., Hayashib, S., Domenc, K. and Haraa, M. (2006) Esterification of Higher Fatty Acids by a Novel Strong Solid Acid. Catalysis Today, 116, 157-161. http://dx.doi.org/10.1016/j.cattod.2006.01.037

[19] Mo, X., Lopez, D., Suwannakarn, K., Liu, Y., Lotero, E., Goodwin Jr., J.G. and Lu, C. (2008) A Novel Sulfonated Carbon Composite Solid Acid Catalyst for Biodiesel Synthesis. Journal of Catalysis, 254, 332-338. http://dx.doi.org/10.1016/j.jcat.2008.01.011

[20] Zong, M.-H., Duan, Z.-Q., Lou, W.-Y., Smith, T.J. and Wu, H. (2007) Preparation of a Sugar Catalyst and Its Use for Highly Efficient Production of Biodiese. Green Chemistry, 9, 434-437. http://dx.doi.org/10.1039/b615447f

[21] Doe, P.H., Wade, W.H. and Schechter, R.S. (1977) Alkyl Benzene Sulfonates for Producing Low Interfacial Tensions between Hydrocarbons and Water. Journal of Colloid and Interface Science, 59, 525-531. http://dx.doi.org/10.1016/0021-9797(77)90048-0

[22] Yang, J., Zhao, Y., Li, Z.S., Qiao, W.H. and Cheng, L.B. (2005) Interfacial Tension Behavior of Mono-Isomeric Phenyltetradecane Sulfonates. Energy Sources, 27, 1013-1018. http://dx.doi.org/10.1080/00908310490450953

[23] Zhao, Y., Xu, Z.G., Li, Z.S., Qiao, W.H. and Cheng, L.B. (2006) Synthesis and Interfacial Tension Behavior of Heavy Alkyl Benzene Sulfonates. Petroleum Science and Technology, 24, 821-827. http://dx.doi.org/10.1081/LFT-200041180

[24] Yu, T., Li, Z., Tong, W., Ding, W., Luo, S.-Q. and Luan, H.X. (2010) Molecular Organized Assemblies Formed by Tetradecyl Aryl Sulfonate. Acta Physico-Chimica Sinica, 26, 317-323.

[25] National Standard GB/T6489-2-1986.

[26] National Standard GB/T6489-3-1986.

[27] Firestone, D. (2001) Official Methods and Recommended Practices of the American Oil Chemists Society. 4th Edition, AOCS Press, 8-53.

[28] Titirici, M.-M., Antonietti, M. and Baccile, N. (2008) Hydrothermal Carbon from Biomass: A Comparison of the Local Structure from Poly- to Monosaccharides and Pentoses/Hexoses. Green Chemistry, 10, 1204-1212. http://dx.doi.org/10.1039/b807009a

[29] Budarin, V., Luque, R., Macquarrie, D.J. and Clark, J.H. (2007) Towards a Bio-Based Industry: Benign Catalytic Esterifications of Succinic Acid in the Presence of Water. Chemistry-A European Journal, 13, 6914-6919. http://dx.doi.org/10.1002/chem.200700037

[30] Zhang, B.H., Ren, J.W., Liu, X.H., Guo, Y., Guo, Y.L., Lu, G.Z. and Wang, Y.Q. (2010) Novel Sulfonated Carbonaceous Materials from $p$-Toluenesulfonic Acid/Glucose as a High-Performance Solid-Acid Catalyst. Catalysis Communications, 11, 629-632. http://dx.doi.org/10.1016/j.catcom.2010.01.010

[31] Tsubouchi, N., Xu, C.B. and Ohtsuka, Y. (2003) Carbon Crystallization during High-Temperature Pyrolysis of Coals and the Enhancement by Calcium. Energy \& Fuels, 17, 1119-1125. http://dx.doi.org/10.1021/ef020265u

[32] Lou, W.Y., Zong, M.H. and Duan, Z.Q. (2008) Efficient Production of Biodiesel from High Free Fatty Acid-Containing Waste Oils Using Various Carbohydrate-Derived Solid Acid Catalysts. Bioresource Technology, 99, 8752-8758. http://dx.doi.org/10.1016/j.biortech.2008.04.038

[33] Nakajima, K. and Hara, M. (2007) Environmentally Benign Production of Chemicals and Energy Using a CarbonBased Strong Solid Acid. Journal of American Ceram Society, 90, 3725-3734. 